\title{
Temporal control of epigenetic centromere specification
}

\author{
Luis P. Valente • Mariana C. C. Silva • Lars E. T. Jansen
}

Published online: 28 June 2012

(C) Springer Science+Business Media B.V. 2012

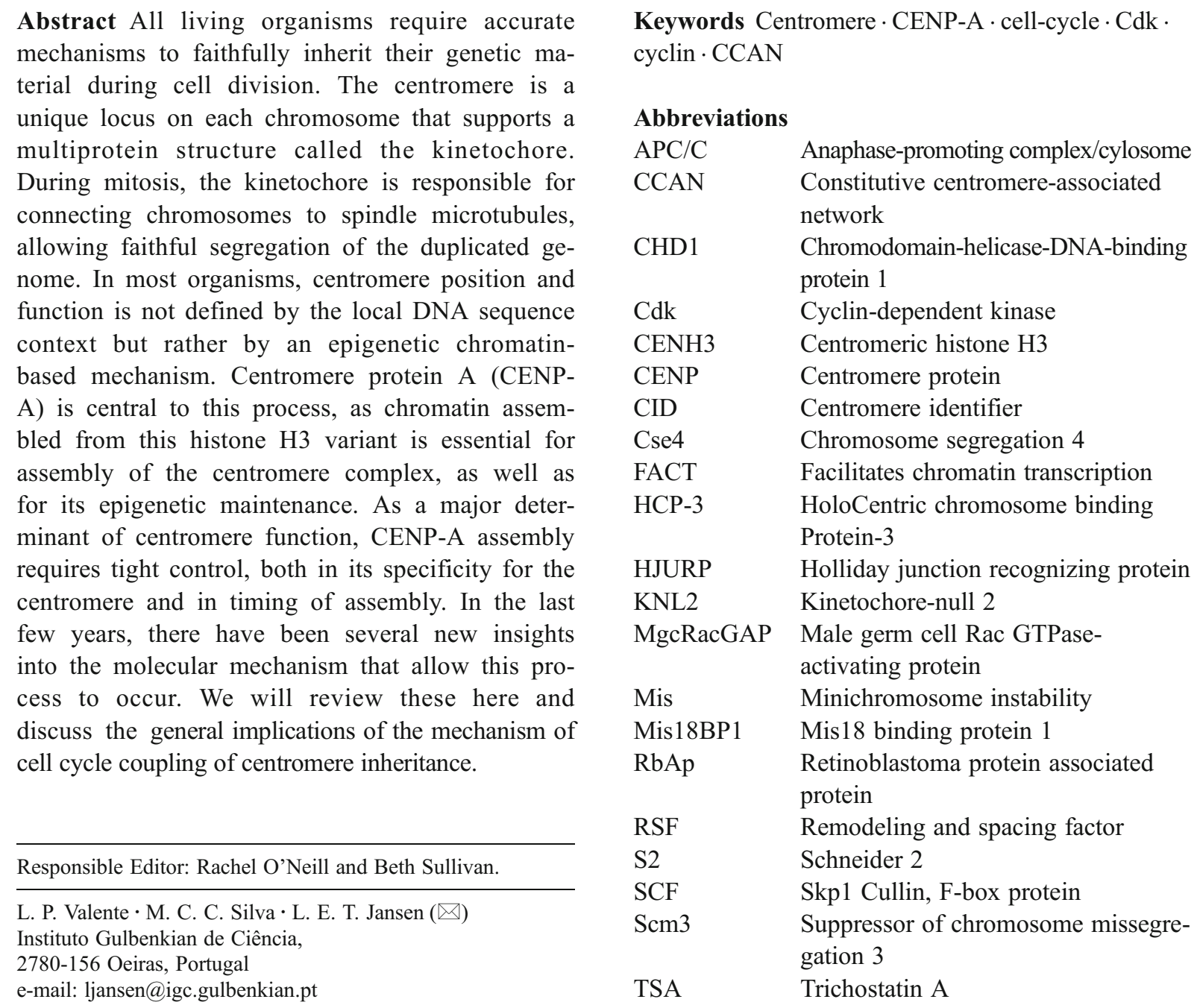




\section{Introduction}

Cell division requires the coordinate action of mechanisms that duplicate the full complement of the genome and subsequently partition these copies among newly formed daughter cells. Key to the latter process of chromosome segregation is a chromosomal region called the centromere. This region, initially defined cytologically as the primary constriction on metazoan metaphase chromosomes, is the site of assembly of a large complex of proteins that function in tethering sister chromatids together as well as in generating attachments to spindle microtubules in a bipolar fashion (Fig. 1). Microtubule binding is mediated by the kinetochore, a complex of proteins that is assembled onto the centromere complex during mitosis.

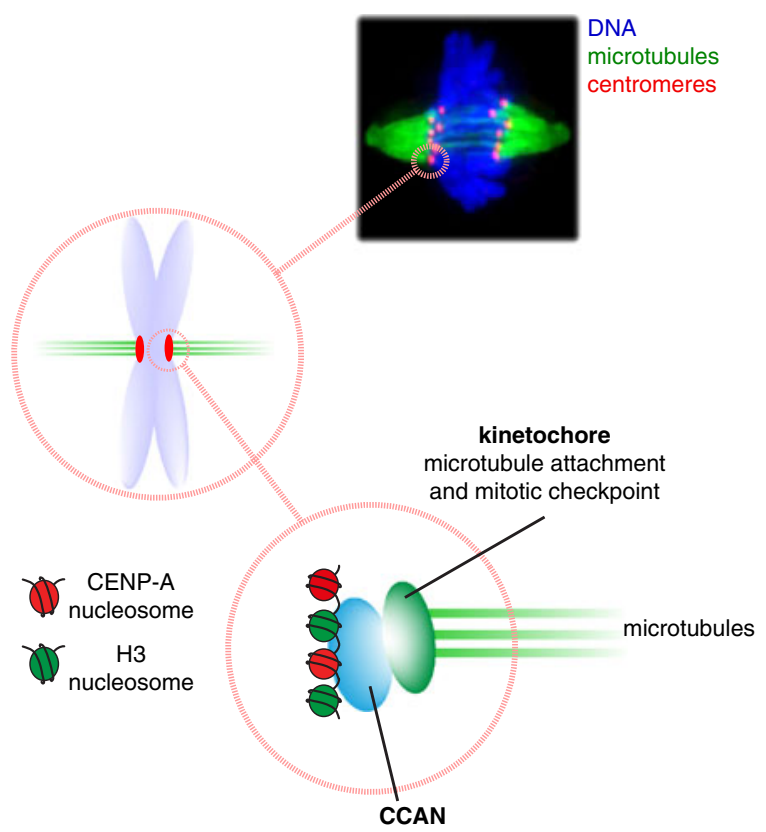

Fig. 1 The centromere, a chromatin locus essential for chromosome segregation. Schematic representation of a metazoan monocentric centromere. Centromeres are nucleoprotein complexes that form on a single locus on each chromosome and form the attachment site for spindle microtubules. Centromeric chromatin is distinguished from general chromatin by the presence of CENP-A containing nucleosomes, which are interspersed with histone H3 nucleosomes. CENP-A chromatin is the site of assembly of the constitutive centromere-associated network (CCAN), which in turn nucleates the kinetochore, a group of proteins with microtubule binding activity and proteins required for mitotic checkpoint signaling. This complex organization allows for proper chromosome segregation by ensuring bipolar attachment of the two sister chromatids during metaphase and drives separation of sisters during anaphase
Centromeres are propagated largely independently of cis-acting DNA sequences indicating they are maintained through an epigenetic mechanism. We will discuss recent evidence implicating the unique chromatin structure that is generated by the histone $\mathrm{H} 3$ variant CENP-A (centromere protein A) in epigenetic maintenance of centromeres. In addition, we will discuss work in both fly and human cells that has shed light on the temporal dynamics of CENP-A chromatin. Determining how centromeric chromatin turns over across the cell division cycle is crucial to understand how CENP-A, as a key component of the epigenetic mechanism at centromeres, is itself inherited and duplicated. We will present recent findings and outline differences and commonalities among different organisms. Finally, we will discuss the consequences of the unique timing of centromeric chromatin assembly for maintenance of centromere function and architecture.

The role of DNA sequence in centromere specification

Contrary to what is observed in Saccharomyces cerevisiae, where a specific 125-bp sequence is sufficient for centromere formation, in most eukaryotes, the centromere typically forms on a subset of long arrays of repetitive DNA. In humans, such DNA regions are comprised of repetitive arrays of 171-bp sequences called $\alpha$-satellites (or alphoid DNA), that can span several megabases (Schueler and Sullivan 2006). One of the first centromeric proteins described, Centromere Protein B (CENP-B) was found to bind specifically to those repeats suggesting that this DNA sequence is important for centromere function (Masumoto et al. 1989). While maintenance of pre-existing centromeres appears largely independent of the underlying DNA sequence (discussed below), centromeric DNA is essential for generating centromeres de novo, both in fission yeast and human cells (Takahashi et al. 1992; Harrington et al. 1997). In human cells, it was further shown that both alphoid DNA and the presence of CENP-B binding sites are important for de novo centromere formation (Ohzeki et al. 2002). However, apart from the mammalian CENP-B box, identifying what sequence features of centromeric DNA are important for centromere formation has been challenging, principally because the highly repetitive tandem sequence repeats present in metazoan centromeres are not conserved among species or, in the case of, e.g., human centromeres, even among different chromosomes of an individual organism (Willard 1991). 
This suggests that the role of DNA sequences at the centromere is to provide a structural context rather than a specific sequence motif.

The epigenetic inheritance of centromeres

Despite its requirement for centromere establishment, there is little support for a prominent role of centromeric DNA in the maintenance of existing centromeres. Evidence against such role came initially from the characterization of stably transmitted dicentric chromosomes in humans and flies. Two active centromeres on a single chromosome may be deleterious to the cell, leading to chromosome breakage and loss. However, dicentric chromosomes can be inherited by inactivating one of the centromeres, without changing its DNA sequence (Earnshaw and Migeon 1985), in a process that is still poorly understood. This indicates that canonical centromere sequences are not sufficient for centromere function. In addition to insufficiency, several lines of evidence have demonstrated that centromeric DNA is also not necessary for the maintenance of centromeres. While CENP-B binding sites are critical for de novo formation of centromeres, the CENP-B protein is nonessential in mice, indicating that as long as preassembled centromeres are inherited, CENP-B binding to centromeres is not required (Hudson et al. 1998; Kapoor et al. 1998; Perez-Castro et al. 1998).

The most direct evidence demonstrating centromere maintenance in the absence of specific DNA sequence elements in cis was provided by the discovery of human neocentromeres which are formed in genomic regions lacking any characteristic centromeric DNA sequences (Voullaire et al. 1993). At such neocentromeres, all essential centromere and kinetochore proteins tested thus far (except CENP-B) are associated with non-repetitive, non-alphoid DNA (Bassett et al. 2010). Since its discovery almost 20 years ago, around 100 unique neocentromeres have been described (Marshall et al. 2008). While neocentromeres often occur on the same chromosome arm (e.g. the q-arms of chromosome 3,13, and 15), fine-mapping of centromere proteins at 3 neocentromeres on $13 \mathrm{q} 32$ revealed that formation of centromeric chromatin occurred on different DNA sequences (Alonso et al. 2003). The absence of true "hotspots" for binding of the centromeric histone, CENP-A, highlights the independence of centromere formation from the DNA sequence. Neocentromeres are stably transmitted during mitosis and in some cases are even germ-line transmitted (Tyler-Smith et al. 1999). These observations led to the proposal that centromere function and propagation is not dependent on any specific DNA sequence, but instead is mediated through an epigenetic mechanism (Karpen and Allshire 1997; Vafa and Sullivan 1997; Warburton et al. 1997).

Neocentromere formation is not limited to Homo sapiens and has been described in a wide range of organisms. In Candida albicans, following the replacement of the centromere of chromosome 5 with a reporter gene, cells were able to maintain this chromosome by forming neocentromeres either distally, at loci around 200 to $450 \mathrm{~kb}$ away from where the reporter is located, or immediately adjacent to the insertion (Ketel et al. 2009). Similarly, in Schizosaccharomyces pombe, in which cen I (centromere from chromosome I) is deleted, neocentromeres have also been identified (Ishii et al. 2008). ChIP-chip analysis of the centromere proteins Mis6 and CENP-A showed that neocentromeres were frequently formed either proximal to the left or the right telomere close to, but not in contact with, subtelomeric heterochromatin (Ishii et al. 2008). Interestingly, in Drosophila, centromere formation can be driven by overexpression of CENP-A. These ectopic centromeres also have the propensity to form adjacent to heterochromatin domains, suggesting a role for heterochromatin in neocentromere formation (Olszak et al. 2011). However, such a role does not appear to be universally required for centromere formation as at least a subset of human neocentromeres appear to lack appreciable heterochromatin (Alonso et al. 2010).

\section{CENP-A: A key epigenetic centromere mark}

The epigenetic mode of centromere transmission finds its basis in a unique local chromatin structure. Early experiments in fission yeast addressed the behavior of reporter genes inserted within pericentromeric heterochromatin in the presence of Trichostatin A (TSA), an inhibitor of histone deacetylases. Treatment with TSA led to high levels of histone acetylation and consequently centromere silencing was alleviated and centromere function was impaired. This chromatin state at the centromere was found to be inherited throughout cell divisions, even in the absence of TSA, suggesting that the assembly of functional centromeres is at least partially imprinted in local chromatin (Ekwall et al. 1997). 
In contrast to pericentromeric heterochromatin, the kinetochore-forming domain of the centromere is differentiated from the rest of the chromosome by the presence of CENP-A, a histone $\mathrm{H} 3$ variant that replaces the canonical histone $\mathrm{H} 3$ in nucleosomes at active centromeres (Palmer et al. 1991). CENP-A is a wellconserved protein that has been identified in a broad range of eukaryotes, including $S$. cerevisiae (Cse4), $S$. pombe (Cnp1), Caenorhabditis elegans (HCP-3), Drosophila melanogaster (CID), Arabidopsis thaliana (CENH3), Xenopus laevis, Gallus gallus, and H. sapiens (CENP-A). CENP-A is critical for the formation of the centromere/kinetochore complex (Foltz et al. 2006) and depletion of CENP-A, in all organisms tested so far, leads to loss of many centromere/kinetochore proteins and failure in chromosome segregation (Howman et al. 2000; Blower and Karpen 2001; Oegema et al. 2001; Régnier et al. 2005; Liu et al. 2006).

The conserved role of this histone variant and its constitutive localization at all active centromeres throughout the cell cycle make CENP-A a strong candidate for a major function in centromere specification and propagation (Allshire and Karpen 2008; Silva and Jansen 2009). Indeed, recent studies provide direct evidence that CENP-A acts as a seed that is both necessary and sufficient for the formation of a fully functional centromere (Barnhart et al. 2011; Mendiburo et al. 2011). In Drosophila S2 cells, tethering CENP-A ${ }^{\text {CID }}$ LacI fusion protein to stably integrated $\mathrm{LacO}$ arrays leads to the formation of functional ectopic centromeres. Furthermore, ectopic CENP-A ${ }^{\mathrm{CID}}$ was capable of assembling a functional kinetochore and direct normal CENP-A $^{\mathrm{CID}}$ (lacking the LacI-anchor) binding to the ectopic site (Mendiburo et al. 2011). A similar approach was used in human U2OS cells by tethering the Holliday Junction Recognizing Protein (HJURP), a CENP-A specific chaperone necessary for CENP-A assembly (Dunleavy et al. 2009; Foltz et al. 2009). In this study, LacO targeted HJURP resulted in the stable recruitment of CENP-A to the array, functional kinetochore formation and stable kinetochore-microtubule attachments (Barnhart et al. 2011). In these tethering experiments, the presence of two centromeres (the endogenous and the ectopic one) led to mitotic failure, preventing the analysis of the long-term fate of the ectopic centromere. To overcome this, Mendiburo et al. employed a plasmid-based artificial chromosome containing $\mathrm{LacO}$ arrays to assess the heritability of ectopic centromeres across cell divisions in Drosophila
S2 cells (Mendiburo et al. 2011). Normally, these plasmids undergo DNA replication but cannot segregate accurately, and are therefore lost within several cell cycles. Similar to the chromosomal $\mathrm{LacO}$ insertions described above, tethering CENP-A ${ }^{\mathrm{CID}}$-LacI fusion protein to the $\mathrm{LacO}$ arrays on those plasmids led to the recruitment of centromeric proteins and to microtubule binding. Critically, these ectopic centromeres promote stable transmission of the plasmids for multiple cell divisions, even in the absence of the fusion protein that initiated centromere formation. Together, these results provide direct evidence that CENP-A is sufficient to direct centromere formation and can initiate a selfperpetuating epigenetic feedback mechanism that controls centromere identity and stable inheritance (Fig. 2). In agreement with these findings, CENP-A nucleosomes are remarkably stable and turn over only upon replication by redistribution to the two sister chromatids (Régnier et al. 2005; Jansen et al. 2007; Hemmerich et al. 2008). Such stability provides further evidence for a key role for CENP-A in the maintenance of centromere identity.

With CENP-A taking center stage in the propagation of the centromere through an epigenetic mechanism, what then is the role of alphoid DNA in centromere formation and maintenance? While no clear role has been ascribed, it is interesting to note that inactive human alphoid arrays at chromosomally integrated sites show a variegating low level of CENP-A (Nakano et al. 2003), indicating that alphoid DNA may be a preferred substrate for CENP-A containing chromatin. This suggests that, while DNA sequence or a particular sequence context is dispensable for maintenance of CENP-A per se, alphoid DNA may facilitate centromere maintenance at multigenerational timescales.

Factors involved in cell cycle dependent assembly of CENP-A

Current evidence is consistent with a role of CENP-A in epigenetically specifying centromere identity through a chromatin-based positive feedback mechanism. This suggests that tight coordination must exist between the duplication of centromeric DNA, replication of centromeric chromatin and cell division. Interestingly, contrary to canonical histones, in human cells, CENP-A loading does not occur during S phase (Shelby et al. 2000; Jansen et al. 2007). Direct evidence for the timing of assembly of nascent CENP-A 




Fig. 2 Model for the seeding and epigenetic propagation of centromeres. CENP-A is targeted to a naive LacO marked chromatin locus either by direct fusion to LacI [CENP-A ${ }^{\text {CID }}$ in Drosophila S2 cells (Mendiburo et al. 2011)] or through recruitment by the LacI-tethered chaperone HJURP [human CENP-A in U2OS cells (Barnhart et al. 2011)]. Tethering of CENP-A results in the nucleation of CENP-A chromatin. This in turn leads to functional centromere and kinetochore formation and triggers the propagation of CENP-A chromatin in a selftemplating manner (likely through an adaptor intermediate) without the need for the initial LacI-seed. Once formed, CENP-A chromatin propagation and turnover through cell divisions reach an equilibrium resulting in stable inheritance of this epigenetic centromere mark

came from SNAP-based fluorescent pulse labeling experiments that allowed visualization of the newly synthesized pool of CENP-A. Despite constitutive CENP-A expression under these conditions, assembly into centromeric chromatin occurs only after exit from mitosis, in early G1 phase (Jansen et al. 2007). In agreement, measurements of steady state CENP-A across the cell cycle and photo-bleaching experiments assessing CENP-A exchange rates also established that the protein is a stable centromeric component that loads upon mitotic exit (Schuh et al. 2007; Hemmerich et al. 2008). Several factors that control the temporal loading of CENP-A have been identified to date. One of them, Mis18, was first identified in fission yeast and was shown to be required for CENP-A localization (Hayashi et al. 2004). In humans, a complex of proteins that includes the Mis18 homologues Mis $18 \alpha$ and Mis18 $\beta$, as well as Mis18BP $1^{\mathrm{HsKNL} 2}$, is essential for CENP-A loading at the centromere (Fujita et al. 2007). Moreover, all three proteins show a similar temporal localization pattern: targeting to the centromere just prior to CENP-A assembly during anaphase and leaving around 2 to $3 \mathrm{~h}$ later, in mid G1 (Fujita et al. 2007; Maddox et al. 2007; Silva and Jansen 2009). Despite their critical role in CENP-A assembly, none of these proteins appear to interact directly with CENP-A (Hayashi et al. 2004; Fujita et al. 2007; Lagana et al. 2010), suggesting an indirect role for this complex. The fact that the Mis18 complex arrives prior to CENP-A assembly led to the proposal that it works as a licensing factor, perhaps by altering its surrounding chromatin environment (Fujita et al. 2007). Changing global acetylation levels by treatment of cells with TSA, a histone deacetylase inhibitor was reported to suppress a Mis18 defect, suggesting that the Mis 18 complex changes local acetylation status (Fujita et al. 2007). Although this result has been disputed (Kim et al. 2012), recent work has shown that CENP-A assembly and functional centromere formation on alphoid DNA that also bears Tet operator sequences can be stimulated by local TetR-mediated tethering of Mis18 or by tethering of histone acetyl transferases (Ohzeki et al. 2012). One possible model is that the Mis18 complex includes a, yet to be defined, histone acetyl transferase that modifies local chromatin in a way that renders it permissive for CENP-A assembly.

The CENP-A specific chaperone $\mathrm{Scm} 3$ in fission yeast and its homologue HJURP in human cells also play a key role in CENP-A assembly (Dunleavy et al. 2009; Foltz et al. 2009; Pidoux et al. 2009; SanchezPulido et al. 2009; Williams et al. 2009). HJURP colocalizes with CENP-A at centromeres during late telophase/early G1, and has the capacity to promote CENPA chromatin assembly in vitro (Barnhart et al. 2011). This work also reported that the Mis18 complex is required for HJURP recruitment to the centromere, and that artificial tethering of HJURP to a chromosomal site is able to promote CENP-A loading in the absence of Mis18. This suggests that Mis18 functions to allow HJURP access to the centromere. However, the molecular details of such a role are still unknown. Contrary to the interaction reported between fission yeast $\mathrm{Scm} 3$ and Mis18 (Pidoux et al. 2009; Williams et al. 2009), in 
human cells, a direct interaction between HJURP and Mis18 complex has not been described. Interestingly, the $\mathrm{RbAp} 46 / 48$ proteins have been found to interact with both the Mis 18 complex and HJURP (Dunleavy et al. 2009; Lagana et al. 2010) providing a possible link between these two key CENP-A assembly factors.

Other players that participate in CENP-A assembly have been identified: Rsf-1, a member of the ATPdependent chromatin remodeling and spacing factor (RSF) complex, and MgcRacGAP (Perpelescu et al. 2009; Lagana et al. 2010). Like the Mis18 complex and HJURP, these novel players localize at the centromere in a cell cycle dependent manner, but do so later, during mid and late G1 phase, respectively. This suggests they are involved in a different step of the CENP-A assembly process that appears drawn out over the length of G1 phase.

Mechanisms of cell cycle control of CENP-A assembly

While many of the components of the CENP-A assembly machinery have been identified, how they recognize centromeres specifically and how they are controlled in the cell cycle is unclear. Recently, we and others have made advances on this latter point. Timing of assembly of new CENP-A coincides with the conclusion of mitosis, but the mitotic signal that initiates centromere propagation remained unidentified. Previously, different models have been proposed implicating mitotic events in CENP-A assembly that include microtubule mediated forces, kinetochore formation, nuclear architecture or destruction of an inhibitor of CENP-A assembly (Mellone and Allshire 2003; Carroll and Straight 2006; Jansen et al. 2007; Allshire and Karpen 2008; Erhardt et al. 2008). SNAP-based pulse-chase labeling, which allows for the specific visualization of newly synthesized CENP-A, has been employed to demonstrate G1 phase-restricted timing of CENP-A assembly (Jansen et al. 2007). Using this methodology, we have recently dissected the mechanism of cell cycle control of CENP-A assembly and shown that timing of CENP-A loading at centromeres is controlled by cyclin-dependent kinases (Cdks) (Silva et al. 2012). Cdks are serine/threonine protein kinases that, through phosphorylation of a large number of downstream targets, are responsible for driving key steps in the cell cycle. Cdks function depends on their association with specific cyclins that confer both activity and substrate specificity (Pagliuca et al. 2011). While Cdk levels remain relatively constant, cyclins oscillate during the cell cycle, driven by waves of cyclin gene expression and targeted protein destruction. Interphase cyclins are ubiquitinated by the Skp1/ Cullin/F-box protein (SCF) complex, while mitotic cyclins are targeted for degradation by the anaphasepromoting complex/cyclosome (APC/C). This combination of $\mathrm{Cdk}$ phosphorylation and cyclin degradation allows for a proper sequence of cell cycle events in a unidirectional manner (Pines and Hagan 2011).

Constitutive expression of CENP-A throughout the cell cycle does not override G1 phase-restricted assembly indicating that assembly is actively prevented in S, G2, and mitotic phases of the cell cycle (Jansen et al. 2007). During these stages, the cell cycle is controlled primarily by Cdk2/cyclin A and Cdk1/cyclin B complexes. A key observation from our work has been that inhibition of Cdk activity using pan-Cdk inhibitors such as Roscovitine is sufficient to drive stable assembly of CENP-A prior to mitosis in human cells (Silva et al. 2012). These results rule out a specific involvement of mitotic events in signaling CENP-A assembly, except for the down regulation of $\mathrm{Cdk}$ activity during mitotic exit. Importantly, this process is independent of APC/C mediated proteolysis and protein synthesis indicating that turning on CENP-A assembly does not require synthesis or destruction of a specific CENP-A assembly activator or inhibitor, respectively. Furthermore, chicken DT40 cells carrying defined mutations in Cdk1 and Cdk2 lose cell cycle control of CENP-A assembly, leading to CENP-A loading throughout the cell cycle. Not only do these experiments corroborate the initial results using broad Cdk inhibitors, they also demonstrate that Cdk1 and Cdk2 are sufficient to maintain CENP-A assembly at bay.

CENP-A assembly factors such as HJURP or members of the Mis 18 complex localize to the centromere in a cell cycle dependent fashion (Fujita et al. 2007; Maddox et al. 2007; Dunleavy et al. 2009; Foltz et al. 2009). Like CENP-A assembly, the timing of localization of these assembly factors can be manipulated by controlling Cdk activity (Silva et al. 2012). Most known CENP-A assembly factors are phosphorylated in vivo (Olsen et al. 2006; Dephoure et al. 2008; Wang et al. 2008; Mayya et al. 2009). Strikingly, mutations in Mis $18 \mathrm{BP} 11^{\mathrm{HsKNL} 2}$ that prevent its phosphorylation are targeted to centromere prematurely, prior to mitosis. This observation, along with the role of Cdk1 and Cdk2 in maintaining cell cycle 
control, has led to a model in which temporal regulation of CENP-A assembly is achieved by Cdk-dependent phosphorylation of CENP-A assembly factor(s), preventing their localization to the centromere, consequently impeding CENP-A assembly outside G1 (Fig. 3). While Mis $18 \mathrm{BP} 1^{\mathrm{HsKNL} 2}$ has emerged as a likely target of control, additional players are possibly involved as Mis18BP1 ${ }^{\mathrm{HsKNL} 2}$ presence at G2 phase centromeres is not sufficient to promote CENP-A assembly (Silva et al. 2012).

Conservation and differences of temporal control among eukaryotes

Loading of CENP-A homologues across different species occurs in a cell cycle regulated fashion. In $S$. pombe, using a temperature sensitive allele of a fluorescently tagged version of CENP-A ${ }^{\mathrm{Cnp} 1}$, it was shown that CENP-A ${ }^{\text {Cnp1 }}$ re-incorporation following a shift to the permissive temperature occurs during two discrete cell cycle phases: early $\mathrm{S}$ and, to a lesser extent, G2 phase (Takayama et al. 2008). While interpretation of experiments based on such ts-alleles is difficult, they suggest that CENP-A is assembled primarily upon mitotic exit (that in fission yeast is immediately followed by $\mathrm{S}$ phase), consistent with observations in human cells. Interestingly, $\mathrm{Scm} 3$, a key HJURP-like factor in fission yeast, is phosphorylated at a putative Cdk consensus site (Pidoux et al. 2009). It is possible that such phosphorylation event takes place during mitosis, coinciding with loss of $\mathrm{Scm} 3$ from the centromere. Like fission yeast, $D$. melanogaster syncytial embryos also miss a G1 phase (Lee and Orr-Weaver 2003), and CENP-A ${ }^{\mathrm{CID}}$ assembly occurs in a tight window during anaphase. As is the case in human cells, CENP-A ${ }^{\text {CID }}$ assembly is strictly dependent on exit from mitosis (Schuh et al. 2007). Interestingly, and in apparent contrast to the



Fig. 3 Model for cell cycle control of CENP-A assembly. Cdk1 and Cdk2 activities maintain the CENP-A assembly machinery in an inactive non-centromeric state through phosphorylation of Mis18BP $1^{\text {HsKNL2 }}$ and possibly other components. Cartoon illustrates Cdk1/Cdk2-mediated inhibition of CENP-A assembly, accomplished in part through phosphorylation (P) of Mis18BP1 $1^{\text {HsKNL2 }}$ (member of the Mis18 complex) during S, G2 and M phases. Phosphorylation of HJURP and/or other unknown factors (symbolized by $\mathrm{X}, \mathrm{Y}$ ) may also be required for this inhibition. Inhibition is alleviated trough $\mathrm{APC} / \mathrm{C}$ mediated destruction of cyclin $\mathrm{B}$ and consequent loss of Cdk1 activity in anaphase. This allows targeting of the Mis18 complex to the centromere in anaphase (licensing) followed by HJURP targeting and CENP-A assembly in G1 phase. CENP-A assembly possibly involves an exchange with H3.3 (Dunleavy et al. 2011). Canonical (H3.1 containing) nucleosomes are shown in light blue, H3.3 nucleosomes in green and CENP-A nucleosomes in red 
studies described above, in Drosophila S2 and Kc167 cells, assembly of CENP-A ${ }^{\mathrm{CID}}$ occurs in metaphase (Mellone et al. 2011). Cdk1 activity peaks in metaphase indicating that possibly, in this case, the role of Cdks in blocking CENP-A ${ }^{\mathrm{CID}}$ assembly is not conserved. Another possibility is that the cyclin/Cdk complexes involved in cell cycle restricting CENP-A ${ }^{\mathrm{CID}}$ assembly are different in these cells. Cyclin A is degraded in early mitosis (den Elzen and Pines 2001; Geley et al. 2001; Huang and Raff 2002) while Cdk1 activity in prometaphase and metaphase is maintained by cyclin B. Possibly, CENP-A ${ }^{\text {CID }}$ assembly in Drosophila is maintained in an inhibitory state exclusively by cyclin A driven Cdk activities during $\mathrm{S}$ and G2 phases, initiating the onset of CENP-A ${ }^{\mathrm{CID}}$ assembly in prometaphase. Consistently, Cal1, a CENP$\mathrm{A}^{\mathrm{CID}}$ assembly factor in flies, targets to centromeres at this stage in mitosis. Furthermore, the Mellone et al. study demonstrated that CENP-A ${ }^{\text {CID }}$ assembly can be prevented by expression of non-degradable cyclin A. Although the cell cycle regulation of CENP-A CID appears to be different between Drosophila cell lines and syncytial embryos, control may nevertheless be limited to Cdk-cyclin A in both systems. However, cyclin A degradation may be differentially regulated in these two cell types. In agreement with this, in Drosophila syncytial embryos, cyclin B is only partially degraded upon mitotic exit and is not essential for mitosis (Knoblich and Lehner 1993; Raff et al. 2002). Cyclin B is therefore an unlikely candidate to play a critical role in controlling the timing of centromere propagation. Instead, mitotic exit may be regulated primarily by loss Cdk-cyclin A activity. Cyclin A is essential for mitosis and its levels are maintained until anaphase during the initial mitotic divisions of the D. melanogaster syncytial embryo (Lehner and O'Farrell 1989) potentially preventing CENP-A CID assembly until mitotic exit in this system. While this awaits a definitive test, these observations appear consistent with a differential role of cyclin A and B in maintaining cell cycle control of CENP-A assembly in Drosophila.

\section{Cell cycle control of the CCAN}

A number of proteins, commonly referred to as the constitutive centromere-associated network (CCAN) associate with CENP-A chromatin throughout the cell cycle and are considered core components maintaining centromere structure (Foltz et al. 2006; Okada et al. 2006; Cheeseman and Desai 2008). While dependent on CENP-A chromatin for their recruitment to centromere (Liu et al. 2006), they in turn can influence assembly of nascent CENP-A. Examples of such components are CENP-H, CENP-I and CENP-K, three proteins that are present as a complex and are required to recruit newly synthesized CENP-A to centromeres (Okada et al. 2006), possibly by recruitment of the FACT1 and CHD1 chromatin modulators, that are in turn necessary for CENP-A to be properly assembled (Okada et al. 2009). CENP-N and CENP-C, also CCAN components, have been found to directly bind to CENP-A nucleosomes in vitro and play a role in the recruitment of nascent CENP-A to centromeres in vivo, placing them within the positive epigenetic feedback loop responsible for centromere propagation (Carroll et al. 2009, 2010). While to date no other component of the CCAN has displayed the G1 phase restricted assembly pattern observed for CENP-A, the assembly of several CCAN components is also under cell cycle control. CENP-I has been shown to be stable throughout the cell cycle, except during S phase where a proportion of centromeric CENP-I is turned over, possibly reflecting deposition of nascent CENP-I onto newly replicated centromeres (Hemmerich et al. 2008). In contrast, CENP-N molecules undergo rapid exchange during $\mathrm{G} 1$ phase of the cell cycle, at the time of CENP-A assembly, becoming stably associated to centromeres only after mid S phase (Hellwig et al. 2011), when centromeric DNA is replicated. CENP$\mathrm{C}$, another CENP-A interacting factor (Carroll et al. 2010), is also stably bound to the centromere during mitosis and S phase (Hemmerich et al. 2008). Recently, four CCAN proteins, CENP-T, CENP-W, CENP-S, and CENP-X were found to form a complex functionally and structurally resembling a histone heterotetramer that interacts with and partially wraps DNA in vitro (Nishino et al. 2012). When tethered on a naive chromatin locus, CENP-T along with CENP-C are sufficient to drive kinetochore formation (Gascoigne et al. 2011), indicating that the CENP-T-W-S-X complex, together with CENP$\mathrm{C}$, form the essential kinetochore-forming platform. Analysis of dynamics of the CENP-T/W sub complex reveals dynamics opposite to that of, e.g., CENP-N, with rapid exchange in late $\mathrm{S}$ phase and $\mathrm{G} 2$ while remaining immobile in G1 phase (Prendergast et al. 2011). 
In summary, although the functional role of these divergent dynamic states across the cell cycle remains unclear, what emerges from these studies is that while the CCAN is constitutive at steady state, different components or sub-complexes display different local dynamics. These differences can be orders of magnitude apart, from immobile proteins that last days to hours (CENP-A, -I) to highly dynamic proteins such as CENP-N during G1 phase or CENP-T and -X during $\mathrm{G} 2$ phase that exchange on a second to minute timescale.

Importance of cell cycle control of CENP-A assembly

Despite the fact that CENP-A assembly is tightly cell cycle regulated, the biological significance for such control is still unclear. One possible explanation is that this mechanism allows for a temporal separation of centromeric chromatin assembly from general chromatin assembly. It has been shown that when CENPA expression is limited to $\mathrm{S}$ phase, it is uniformly distributed throughout chromatin (Shelby et al. 1997), indicating that CENP-A can be assembled by the general chromatin assembly machinery. Limiting CENP-A assembly to outside $\mathrm{S}$ phase can therefore help restrict it to the centromere. In fission yeast, CENP-A assembly occurs in early $\mathrm{S}$ phase (Takayama et al. 2008). However, CENP-A gene synthesis precedes bulk H3 synthesis and centromeres are early replicating, potentially facilitating centromere specific deposition of CENP-A even in a system where assembly is overlapping with S phase (Castillo et al. 2007).

G1 phase assembly and subsequent centromeric DNA replication in $\mathrm{S}$ phase creates a condition where during mitosis the centromeres carry only half of the maximum CENP-A complement. It has been proposed (Jansen et al. 2007) and recently shown (Dunleavy et al. 2011) that histone H3 is assembled among CENPA containing nucleosomes during $\mathrm{S}$ phase. It is possible that a mixture of CENP-A/H3 chromatin is important for kinetochore formation and chromosome segregation. The recent finding that CCAN components such as the CENP-T-W-S-X complex can make chromatin contacts independent of CENP-A, either directly to DNA (Gascoigne et al. 2011) or in the context of $\mathrm{H} 3$ chromatin (Hori et al. 2008), fuels this idea. However, whether such H3 chromatin is functionally relevant remains to be tested. In this respect it is important to note that pre-S phase assembly of
CENP-A is not universal. As in a subset of fission yeast cells, measurement of CENP-A ${ }^{\mathrm{CENH} 3}$ levels in plants or amoebozoa centromeres indicates a G2 phase mode of assembly (Dubin et al. 2010; Lermontova et al. 2011), inconsistent with the idea of a delicate $S$ phase generated CENP-A/H3 balance. Nevertheless, some form of cell cycle coupling of CENP-A assembly appears to be universal, indicating the necessity for maintaining a balance between cell division and epigenetic centromere propagation. It is noteworthy that temporal control of CENP-A assembly in vertebrates by the Cdk cycle constitutes an on/off mechanisms in which the turning "on" in early G1 and "off" in late G1 may help to restrict CENP-A assembly to a narrow cell cycle window and in turn maintain centromere size.

\section{Outlook}

The recent flurry in discoveries that provide a more complete understanding on how centromeres work and how they are regulated during the cell cycle have raised many novel questions and left others unanswered. How is centromeric chromatin marked for CENP-A assembly by Mis 18 complex members and how can CENP-A, once assembled survive through chromatin disruption during DNA replication? With respect to cell cycle control questions include: What is the functional role of cell cycle regulation of CCAN assembly and what is the significance of G1 phase restricted assembly of CENP-A? What are the consequences of CENP-A targeting to the centromere outside G1 phase? Moreover, despite the prominent role of Cdk activity in timing CENP-A assembly, the molecular mechanism requires further dissection. Mis $18 \mathrm{BP} 1^{\mathrm{HsKNL} 2}$ appears to be a part of this mechanism of temporal control (Silva et al. 2012) but how its activity is regulated and to which other CENP-A assembly factors this control extends are questions of great interest in future efforts.

Acknowledgments LPV and MCCS are supported by the Fundação para a Ciência e a Tecnologia (FCT) fellowships SFRH/BPD/69115/2010 and SFRH/BD/33219/2007, respectively. This work is supported by the Fundação Calouste Gulbenkian, FCT grants BIA-BCM/100557/2008 and BIA-PRO/100537/ 2008, the European Commission FP7 programme, and an EMBO installation grant to LETJ. 


\section{References}

Allshire RC, Karpen GH (2008) Epigenetic regulation of centromeric chromatin: old dogs, new tricks? Nature reviews 9:923-37

Alonso A, Mahmood R, Li S, Cheung F, Yoda K, Warburton PE (2003) Genomic microarray analysis reveals distinct locations for the CENP-A binding domains in three human chromosome 13q32 neocentromeres. Hum Mol Genet $12: 2711-2721$

Alonso A, Hasson D, Cheung F, Warburton PE (2010) A paucity of heterochromatin at functional human neocentromeres. Epigenetics Chromatin 3:6

Barnhart MC, Kuich PHJL, Stellfox ME, Ward JA, Bassett EA, Black BE, Foltz DR (2011) HJURP is a CENP-A chromatin assembly factor sufficient to form a functional de novo kinetochore. J Cell Biol 194:229-243

Bassett EA, Wood S, Salimian KJ, Ajith S, Foltz DR, Black BE (2010) Epigenetic centromere specification directs aurora $\mathrm{B}$ accumulation but is insufficient to efficiently correct mitotic errors. J Cell Biol 190:177-185

Blower MD, Karpen GH (2001) The role of Drosophila CID in kinetochore formation, cell-cycle progression and heterochromatin interactions. Nat Cell Biol 3:730-739

Carroll CW, Straight AF (2006) Centromere formation: from epigenetics to self-assembly. Trends Cell Biol 16:70-78

Carroll CW, Silva MCC, Godek KM, Jansen LET, Straight AF (2009) Centromere assembly requires the direct recognition of CENP-A nucleosomes by CENP-N. Nat Cell Biol 11:896-902

Carroll CW, Milks KJ, Straight AF (2010) Dual recognition of CENP-A nucleosomes is required for centromere assembly. J Cell Biol 189:1143-1155

Castillo AG, Mellone BG, Partridge JF, Richardson W, Hamilton GL, Allshire RC, Pidoux AL (2007) Plasticity of fission yeast CENP-A chromatin driven by relative levels of histone $\mathrm{H} 3$ and H4. PLoS Genet 3:e121

Cheeseman IM, Desai A (2008) Molecular architecture of the kinetochore-microtubule interface. Nat Rev Mol Cell Biol 9:33-46

den Elzen N, Pines J (2001) Cyclin A is destroyed in prometaphase and can delay chromosome alignment and anaphase. J Cell Biol 153:121-136

Dephoure N, Zhou C, Villén J, Beausoleil SA, Bakalarski CE, Elledge SJ, Gygi SP (2008) A quantitative atlas of mitotic phosphorylation. Proc Natl Acad Sci U S A 105:1076210767

Dubin M, Fuchs J, Gräf R, Schubert I, Nellen W (2010) Dynamics of a novel centromeric histone variant $\mathrm{CenH} 3$ reveals the evolutionary ancestral timing of centromere biogenesis. Nucleic Acids Res 38:7526-7537

Dunleavy EM, Roche D, Tagami H, Lacoste N, Ray-Gallet D, Nakamura Y, Daigo Y, Nakatani Y, Almouzni-Pettinotti G (2009) HJURP is a cell-cycle-dependent maintenance and deposition factor of CENP-A at centromeres. Cell 137:485497

Dunleavy EM, Almouzni G, Karpen GH (2011) H3.3 is deposited at centromeres in $\mathrm{S}$ phase as a placeholder for newly assembled CENP-A in G(1) phase. Nucleus 2:146-157
Earnshaw WC, Migeon BR (1985) Three related centromere proteins are absent from the inactive centromere of a stable isodicentric chromosome. Chromosoma 92:290-6

Ekwall K, Olsson T, Turner BM, Cranston G, Allshire RC (1997) Transient inhibition of histone deacetylation alters the structural and functional imprint at fission yeast centromeres. Cell 91:1021-32

Erhardt S, Mellone BG, Betts CM, Zhang W, Karpen GH, Straight AF (2008) Genome-wide analysis reveals a cell cycle-dependent mechanism controlling centromere propagation. J Cell Biol 183:805-818

Foltz DR, Jansen LET, Black BE, Bailey AO, Yates JR, Cleveland DW (2006) The human CENP-A centromeric nucleosomeassociated complex. Nat Cell Biol 8:458-469

Foltz DR, Jansen LET, Bailey AO, Yates JR, Bassett EA, Wood S, Black BE, Cleveland DW (2009) Centromere-specific assembly of CENP-A nucleosomes is mediated by HJURP. Cell 137:472-484

Fujita Y, Hayashi T, Kiyomitsu T, Toyoda Y, Kokubu A, Obuse C, Yanagida M (2007) Priming of centromere for CENP-A recruitment by human hMis18alpha, hMis18beta, and M18BP1. Dev Cell 12:17-30

Gascoigne KE, Takeuchi K, Suzuki A, Hori T, Fukagawa T, Cheeseman IM (2011) Induced ectopic kinetochore assembly bypasses the requirement for CENP-A nucleosomes. Cell 145:410-422

Geley S, Kramer E, Gieffers C, Gannon J, Peters JM, Hunt T (2001) Anaphase-promoting complex/cyclosome-dependent proteolysis of human cyclin A starts at the beginning of mitosis and is not subject to the spindle assembly checkpoint. J Cell Biol 153:137-148

Harrington JJ, Van Bokkelen G, Mays RW, Gustashaw K, Willard HF (1997) Formation of de novo centromeres and construction of first-generation human artificial microchromosomes. Nat Genet 15:345-355

Hayashi T, Fujita Y, Iwasaki O, Adachi Y, Takahashi K, Yanagida M (2004) Mis16 and Mis18 are required for CENP-A loading and histone deacetylation at centromeres. Cell 118:715-29

Hellwig D, Emmerth S, Ulbricht T, Döring V, Hoischen C, Martin R, Samora CP, McAinsh AD, Carroll CW, Straight AF, Meraldi P, Diekmann S (2011) Dynamics of CENP-N kinetochore binding during the cell cycle. J Cell Sci 124:3871-3883

Hemmerich P, Weidtkamp-Peters S, Hoischen C, Schmiedeberg L, Erliandri I, Diekmann S (2008) Dynamics of inner kinetochore assembly and maintenance in living cells. J Cell Biol 180:1101-1114

Hori T, Amano M, Suzuki A, Backer CB, Welburn JP, Dong Y, McEwen BF, Shang W-H, Suzuki E, Okawa K, Cheeseman IM, Fukagawa T (2008) CCAN makes multiple contacts with centromeric DNA to provide distinct pathways to the outer kinetochore. Cell 135:1039-1052

Howman EV, Fowler KJ, Newson AJ, Redward S, MacDonald AC, Kalitsis P, Choo KH (2000) Early disruption of centromeric chromatin organization in centromere protein A (Cenpa) null mice. Proc Natl Acad Sci U S A 97:1148-1153

Huang J, Raff JW (2002) The dynamic localisation of the Drosophila APC/C: evidence for the existence of multiple complexes that perform distinct functions and are differentially localised. J Cell Sci 115:2847-2856 
Hudson DF, Fowler KJ, Earle E, Saffery R, Kalitsis P, Trowell H, Hill J, Wreford NG, de Kretser DM, Cancilla MR, Howman E, Hii L, Cutts SM, Irvine DV, Choo KH (1998) Centromere protein B null mice are mitotically and meiotically normal but have lower body and testis weights. J Cell Biol 141:309-19

Ishii K, Ogiyama Y, Chikashige Y, Soejima S, Masuda F, Kakuma T, Hiraoka Y, Takahashi K (2008) Heterochromatin integrity affects chromosome reorganization after centromere dysfunction. Science 321:1088-91

Jansen LET, Black BE, Foltz DR, Cleveland DW (2007) Propagation of centromeric chromatin requires exit from mitosis. $\mathrm{J}$ Cell Biol 176:795-805

Kapoor M, de Oca M, Luna R, Liu G, Lozano G, Cummings C, Mancini M, Ouspenski I, Brinkley BR, May GS (1998) The cenpB gene is not essential in mice. Chromosoma 107:570-6

Karpen GH, Allshire RC (1997) The case for epigenetic effects on centromere identity and function. Trends Genet 13:489-496

Ketel C, Wang HS, McClellan M, Bouchonville K, Selmecki A, Lahav T, Gerami-Nejad M, Berman J (2009) Neocentromeres form efficiently at multiple possible loci in Candida albicans. PLoS Genet 5:e1000400

Kim IS, Lee M, Park KC, Jeon Y, Park JH, Hwang EJ, Jeon TI, Ko S, Lee H, Baek SH, Kim KI (2012) Roles of Mis $18 \alpha$ in epigenetic regulation of centromeric chromatin and CENPA loading. Mol Cell 46:260-273

Knoblich JA, Lehner CF (1993) Synergistic action of Drosophila cyclins $\mathrm{A}$ and $\mathrm{B}$ during the G2-M transition. EMBO J 12:65-74

Lagana A, Dorn JF, De Rop V, Ladouceur A-M, Maddox AS, Maddox PS (2010) A small GTPase molecular switch regulates epigenetic centromere maintenance by stabilizing newly incorporated CENP-A. Nat Cell Biol 12:1186-1193

Lee LA, Orr-Weaver TL (2003) Regulation of cell cycles in Drosophila development: intrinsic and extrinsic cues. Annu Rev Genet 37:545-578

Lehner CF, O'Farrell PH (1989) Expression and function of Drosophila cyclin A during embryonic cell cycle progression. Cell 56:957-968

Lermontova I, Rutten T, Schubert I (2011) Deposition, turnover, and release of CENH3 at Arabidopsis centromeres. Chromosoma 120:633-640

Liu S-T, Rattner JB, Jablonski SA, Yen TJ (2006) Mapping the assembly pathways that specify formation of the trilaminar kinetochore plates in human cells. J Cell Biol 175:41-53

Maddox PS, Hyndman F, Monen J, Oegema K, Desai A (2007) Functional genomics identifies a Myb domain-containing protein family required for assembly of CENP-A chromatin. J Cell Biol 176:757-763

Marshall OJ, Chueh AC, Wong LH, Choo KH (2008) Neocentromeres: new insights into centromere structure, disease development, and karyotype evolution. Am J Hum Genet 82:261-82

Masumoto H, Masukata H, Muro Y, Nozaki N, Okazaki T (1989) A human centromere antigen (CENP-B) interacts with a short specific sequence in alphoid DNA, a human centromeric satellite. J Cell Biol 109:1963-73

Mayya V, Lundgren DH, Hwang S-I, Rezaul K, Wu L, Eng JK, Rodionov V, Han DK (2009) Quantitative phosphoproteomic analysis of $\mathrm{T}$ cell receptor signaling reveals system-wide modulation of protein-protein interactions. Sci Signal 2:ra46

Mellone BG, Allshire RC (2003) Stretching it: putting the CEN (P-A) in centromere. Curr Opin Genet Dev 13:191-198

Mellone BG, Grive KJ, Shteyn V, Bowers SR, Oderberg I, Karpen GH (2011) Assembly of Drosophila centromeric chromatin proteins during mitosis. PLoS Genet 7:e1002068

Mendiburo MJ, Padeken J, Fülöp S, Schepers A, Heun P (2011) Drosophila CENH3 is sufficient for centromere formation. Science 334:686-690

Nakano M, Okamoto Y, Ohzeki J, Masumoto H (2003) Epigenetic assembly of centromeric chromatin at ectopic alphasatellite sites on human chromosomes. J Cell Sci 116:4021-4034

Nishino T, Takeuchi K, Gascoigne KE, Suzuki A, Hori T, Oyama T, Morikawa K, Cheeseman IM, Fukagawa T (2012) CENP-T-W-S-X forms a unique centromeric chromatin structure with a histone-like fold. Cell 148:487-501

Oegema K, Desai A, Rybina S, Kirkham M, Hyman AA (2001) Functional analysis of kinetochore assembly in Caenorhabditis elegans. J Cell Biol 153:1209-1226

Ohzeki J, Nakano M, Okada T, Masumoto H (2002) CENP-B box is required for de novo centromere chromatin assembly on human alphoid DNA. J Cell Biol 159:765-775

Ohzeki J-I, Bergmann JH, Kouprina N, Noskov VN, Nakano M, Kimura H, Earnshaw WC, Larionov V, Masumoto H (2012) Breaking the HAC Barrier: Histone H3K9 acetyl/ methyl balance regulates CENP-A assembly. EMBO J 31:2391-2402

Okada M, Cheeseman IM, Hori T, Okawa K, McLeod IX, Yates JR, Desai A, Fukagawa T (2006) The CENP-H-I complex is required for the efficient incorporation of newly synthesized CENP-A into centromeres. Nat Cell Biol 8:446-57

Okada M, Okawa K, Isobe T, Fukagawa T (2009) CENP-Hcontaining complex facilitates centromere deposition of CENP-A in cooperation with FACT and CHD1. Mol Biol Cell 20:3986-3995

Olsen JV, Blagoev B, Gnad F, Macek B, Kumar C, Mortensen P, Mann M (2006) Global, in vivo, and site-specific phosphorylation dynamics in signaling networks. Cell 127:635-648

Olszak AM, van Essen D, Pereira AJ, Diehl S, Manke T, Maiato H, Saccani S, Heun P (2011) Heterochromatin boundaries are hotspots for de novo kinetochore formation. Nat Cell Biol 13:799-808

Pagliuca FW, Collins MO, Lichawska A, Zegerman P, Choudhary JS, Pines J (2011) Quantitative proteomics reveals the basis for the biochemical specificity of the cell-cycle machinery. Mol Cell 43:406-417

Palmer DK, O’Day K, Trong HL, Charbonneau H, Margolis RL (1991) Purification of the centromere-specific protein CENP-A and demonstration that it is a distinctive histone. Proc Natl Acad Sci U S A 88:3734-3738

Perez-Castro AV, Shamanski FL, Meneses JJ, Lovato TL, Vogel KG, Moyzis RK, Pedersen R (1998) Centromeric protein B null mice are viable with no apparent abnormalities. Dev Biol 201:135-143

Perpelescu M, Nozaki N, Obuse C, Yang H, Yoda K (2009) Active establishment of centromeric CENP-A chromatin by RSF complex. J Cell Biol 185:397-407 
Pidoux AL, Choi ES, Abbott JKR, Liu X, Kagansky A, Castillo AG, Hamilton GL, Richardson W, Rappsilber J, He X, Allshire RC (2009) Fission yeast Scm3: A CENP-A receptor required for integrity of subkinetochore chromatin. Mol Cell 33:299-311

Pines J, Hagan I (2011) The renaissance or the cuckoo clock. Phil Trans R Soc B 366:3625-3634

Prendergast L, van Vuuren C, Kaczmarczyk A, Doering V, Hellwig D, Quinn N, Hoischen C, Diekmann S, Sullivan KF (2011) Premitotic assembly of human CENPs -T and -W switches centromeric chromatin to a mitotic state. PLoS Biol 9:e1001082

Raff JW, Jeffers K, Huang J-Y (2002) The roles of Fzy/Cdc20 and $\mathrm{Fzr} / \mathrm{Cdh} 1$ in regulating the destruction of cyclin B in space and time. J Cell Biol 157:1139-1149

Régnier V, Vagnarelli P, Fukagawa T, Zerjal T, Burns E, Trouche D, Earnshaw W, Brown W (2005) CENP-A is required for accurate chromosome segregation and sustained kinetochore association of BubR1. Mol Cell Biol 25:3967-3981

Sanchez-Pulido L, Pidoux AL, Ponting CP, Allshire RC (2009) Common ancestry of the CENP-A chaperones Scm3 and HJURP. Cell 137:1173-4

Schueler MG, Sullivan BA (2006) Structural and functional dynamics of human centromeric chromatin. Annu Rev Genomics Hum Genet 7:301-313

Schuh M, Lehner CF, Heidmann S (2007) Incorporation of Drosophila CID/CENP-A and CENP-C into centromeres during early embryonic anaphase. Curr Biol 17:237-243

Shelby RD, Vafa O, Sullivan KF (1997) Assembly of CENP-A into centromeric chromatin requires a cooperative array of nucleosomal DNA contact sites. J Cell Biol 136:501-513

Shelby RD, Monier K, Sullivan KF (2000) Chromatin assembly at kinetochores is uncoupled from DNA replication. J Cell Biol 151:1113-1118

Silva MC, Jansen LE (2009) At the right place at the right time: novel CENP-A binding proteins shed light on centromere assembly. Chromosoma 118:567-74
Silva MCC, Bodor DL, Stellfox ME, Martins NMC, Hochegger H, Foltz DR, Jansen LET (2012) Cdk activity couples epigenetic centromere inheritance to cell cycle progression. Dev Cell 22:52-63

Takahashi K, Murakami S, Chikashige Y, Funabiki H, Niwa O, Yanagida M (1992) A low copy number central sequence with strict symmetry and unusual chromatin structure in fission yeast centromere. Mol Biol Cell 3:819-35

Takayama Y, Sato H, Saitoh S, Ogiyama Y, Masuda F, Takahashi K (2008) Biphasic Incorporation of Centromeric Histone CENP-A in Fission Yeast. Mol Biol Cell 19:682-90

Tyler-Smith C, Gimelli G, Giglio S, Floridia G, Pandya A, Terzoli G, Warburton PE, Earnshaw WC, Zuffardi O (1999) Transmission of a fully functional human neocentromere through three generations. Am J Hum Genet 64:1440-1444

Vafa O, Sullivan KF (1997) Chromatin containing CENP-A and alpha-satellite DNA is a major component of the inner kinetochore plate. Curr Biol 7:897-900

Voullaire LE, Slater HR, Petrovic V, Choo KH (1993) A functional marker centromere with no detectable alpha-satellite, satellite III, or CENP-B protein: activation of a latent centromere? Am J Hum Genet 52:1153-63

Wang B, Malik R, Nigg EA, Körner R (2008) Evaluation of the low-specificity protease elastase for large-scale phosphoproteome analysis. Anal Chem 80:9526-9533

Warburton PE, Cooke CA, Bourassa S, Vafa O, Sullivan BA, Stetten G, Gimelli G, Warburton D, Tyler-Smith C, Sullivan KF, Poirier GG, Earnshaw WC (1997) Immunolocalization of CENP-A suggests a distinct nucleosome structure at the inner kinetochore plate of active centromeres. Curr Biol 7:901-904

Willard HF (1991) Evolution of alpha satellite. Curr Opin Genet Dev 1:509-514

Williams JS, Hayashi T, Yanagida M, Russell P (2009) Fission yeast Scm3 mediates stable assembly of Cnp1/CENP-A into centromeric chromatin. Mol Cell 33:287-298 